\title{
Characteristics of patients unaware of their chronic hepatitis virus infection
}

\author{
HIROSHI OKANO, HIROKI ASAKAWA, KENJI NOSE, SATOMI TSURUGA, TOMOMASA TOCHIO, \\ HIROAKI KUMAZAWA, TAKASHI SAKUNO, YOSHIAKI ISONO, HIROKI TANAKA, SHIMPEI MATSUSAKI, \\ TOMOHIRO SASE, TOMONORI SAITO, KATSUMI MUKAI and AKIRA NISHIMURA
}

Department of Gastroenterology, Suzuka General Hospital, Suzuka, Mie 513-8630, Japan

Received January 25, 2021; Accepted April 12, 2021

DOI: 10.3892/wasj.2021.100

\begin{abstract}
A number of patients do not benefit from advancements made in the treatment of chronic hepatitis $B$ virus (HBV) and chronic hepatitis $\mathrm{C}$ virus (HCV) infection due to a lack of awareness of their infection. Therefore, the present study aimed to investigate the reason for this and to identify strategies to resolve this issue. Data were retrospectively collected from medical records for the period between 2009 and 2019. Patients with chronic HBV or HCV infection who had been referred to the hospital and were unaware of their infection prior to their referral were eligible to participate in the present study. Overall, 282 and 259 patients with chronic $\mathrm{HBV}$ and $\mathrm{HCV}$ infection, respectively, were referred to the hospital. Of these patients, 63 in each group had been unaware of their infection. Moreover, of the 63 patients, seven already had hepatocellular carcinoma at diagnosis. The female patients with $\mathrm{HCV}$ were older than the other patients, including the male patients and the female patients with $\mathrm{HBV}(\mathrm{P}=0.02)$, and the patients in the HBV group were younger than those in the HCV group $(\mathrm{P}=0.02)$. The majority of the patients $(96 / 126)$ had become aware of their infection by chance. In the HBV group, patients whose infection had been detected during a health checkup were significantly younger than those whose infection had been detected by chance $(\mathrm{P}=0.016)$, but not in the $\mathrm{HCV}$ group. On the whole, these findings suggest that, in order to identify greater numbers of patients with chronic hepatitis infection who are unaware of their infection, the necessity of screening for hepatitis virus in primary care, particularly among women and elderly individuals, should be emphasized and promoted.
\end{abstract}

Correspondence to: Dr Hiroshi Okano, Department of Gastroenterology, Suzuka General Hospital, 1275-53 Yasuduka-cho, Suzuka, Mie 513-8630, Japan

E-mail: oohh1969@yahoo.co.jp

Key words: unawareness of infection, hepatitis B virus, hepatitis C virus, hepatitis virus screening, patient

\section{Introduction}

Worldwide, 248 million and 185 million individuals are chronically infected with chronic hepatitis B virus (HBV) (1) and chronic hepatitis $\mathrm{C}$ virus (HCV), respectively (2). These chronic diseases are a public health burden worldwide as they represent a characteristic and major cause of hepatocellular carcinoma (HCC) $(3,4)$ and cirrhosis. However, the circumstances of patients with chronic HBV and HCV infection have recently improved (5). In Japan, nucleot(s)ide analogs for patients with chronic HBV have led to high virological, biochemical and histological response rates $(6,7)$, and perinatal HBV transmission has been almost completely eliminated (8). Owing to a low incidence of adverse events, the safety of nucleot(s)ide analog treatment for chronic HBV infection has been established (9), and almost all patients with chronic $\mathrm{HCV}$ infection have been cured since the introduction of direct-acting antivirals (DAAs) (10-15). Long-term nucleot(s) ide therapy has led to improvements in cases involving hepatic fibrosis and the clearance of hepatitis B surface antigen (HBsAg) $(16,17)$. Associations have also been found between the sustained virologic response (SVR) induced by DAA treatment for $\mathrm{HCV}$ and significantly lower all-cause mortality and lower incident $\mathrm{HCC}$ rates (18). In addition, the early diagnosis and treatment of $\mathrm{HCV}$ have led to a favorable incremental cost-effectiveness ratio in Japan (19).

Despite these marked improvements in the treatment and prognosis of patients with chronic HBV and HCV infection, a number of patients remain unaware of their infection, and thus cannot receive the benefits of these advancements made in treatment. Moreover, the delayed diagnosis of chronic $\mathrm{HBV}$ or HCV infection can result in disease progression to the advanced stage, where treatment no longer has an impact. In addition, the presence of cirrhosis at the time of SVR in patients with HCV increases the risk of HCC (20). Therefore, the earlier identification and awareness of these infections is necessary to help eliminate these viruses and prevent their associated complications.

Given this background, the present study targeted patients with chronic HBV or HCV infection who were unaware of their disease. As regards the detection of such patients, eligible cases were defined as those whose first awareness of their chronic $\mathrm{HBV}$ or $\mathrm{HCV}$ infection was $<1$ year before being 
referred to Suzuka General Hospital (i.e., individuals who had only recently become aware of their own infection). These patients were analyzed in terms of demographic and clinical features, and the types of opportunities/events they led them to become aware of their chronic HBV or HCV infection. Finally, the present study sought to identify the issues associated with early identification and the awareness of chronic hepatitis infection in Japan.

\section{Patients and methods}

Patient data. The present study retrospectively collected data from medical records at Suzuka General Hospital for the period between January 1, 2009 and December 31, 2019. Patients with chronic HBV or HCV infection who had been referred to the Department of Gastroenterology of the hospital and had been unaware of their infection prior to their referral were included in the study. Patients who had been first aware of their hepatitis virus infection within 1 year prior to their referral were included as being 'unaware of their infection' as they were unaware of their infection until recently. These patients who were unaware of their hepatitis viral infection were eligible to participate in the present study. Oral informed consents, including the statement of agreement to the use of their samples in scientific research were obtained from each patient at the first medical examination in the Outpatient Department of Suzuka General Hospital. The present study was approved by the Ethics Committee of Suzuka General Hospital.

HBV infection was diagnosed as HBsAg-positive and/or HBV DNA-positive, and HCV infection was diagnosed as anti-HCV antibody ( $\mathrm{HCV} \mathrm{Ab}$ ) and HCV RNA-positive. Chronic hepatitis infection, HCC and cirrhosis were diagnosed by ultrasonography, computed tomography (CT) and/or magnetic resonance imaging (MRI), respectively. Cases with a diagnosis of acute hepatitis were excluded from the study.

Serum HBsAg, anti-HBV antibody and HCV Ab levels were measured by chemiluminescent enzyme immunoassay (CLEIA; Fujirebio Co., Ltd.). The measurements of HBV e-antigen, anti-HBV e-antigen, HBV DNA, HBV genotype, HCV RNA, $\mathrm{HCV}$ serogroup and $\mathrm{HCV}$ genotype were performed at LSI Medience Corporation. HCV genotyping was performed when the HCV serotyping could not be determined. Both the aspartate aminotransferase (AST) and alanine aminotransferase (ALT) values were measured using the cobas ${ }^{\circledR} 8000$ modular analyzer series (Roche Diagnosis) or the LABOSPECT008 (Hitachi High-Tech Corporation). The platelet count was measured using the Sysmex XE2100I hematology automated analyzer (Sysmex Corporation). The prothrombin time (PT) values were measured using the Sysmex CS-2500 automated coagulation analyzer (Sysmex Corporation). Blood specimens were obtained by drawing blood from each patient. The serum fraction obtained by the centrifugation $(2,100 \mathrm{x} g$ at room temperature for $5 \mathrm{~min}$ ) of the blood specimens was used for AST and ALT analysis. The whole blood specimen was used for the platelet count analysis. The plasma that was separated using a container with sodium citrate was used for the analysis of the PT values.

Statistical analysis. The patients' age, year of birth, reference laboratory data and the types of opportunities/events that led them to become aware of their chronic HBV or HCV infection were also analyzed. The proportions for each type of opportunity were then calculated and compared between groups. The data are presented as the mean \pm SD. Statistical analysis was conducted using StatView version 5.0 (SAS Institute Inc.). The Mann-Whitney U test was used for the comparisons between groups. The Kruskal-Wallis test was used for multiple comparisons of the data and the Mann Whitney U with Bonferroni's correction was applied for multiple comparisons as a post hoc test. One experiment was performed for each analysis.

\section{Results}

In total, 282 (170 males, 112 females) and 259 (150 male, 109 female) Japanese patients with chronic HBV and HCV infection, respectively, were referred to Suzuka General Hospital between January 1, 2009 and December 31, 2019; among these patients, 63 in each group had no known history of prior infection and had been unaware of their current infection. No cases of HBV/HCV co-infection were found.

The details of the patients with the first awareness of their chronic HBV infection (HBV group) and chronic HCV infection (HCV group) are presented in Table I. The HBV group included 44 male and 19 female patients. Among the 63 patients in the HBV group, 53 were both HBsAg-positive and HBV DNA-positive (38 males, 15 females). Two patients were HBsAg-negative, but HBV DNA-positive, and eight patients were HBsAg-positive, but HBV DNA-negative. From the 44 patients for whom the genotype could be determined, the highest percentage had genotype $\mathrm{C}(79.5 \%)$. In total, two and seven patients had genotypes A and B, respectively. All patients in the HCV group were $\mathrm{HCV}$ Ab- and HCV RNA-positive. Of the 56 patients for whom the genotype could be determined, 35 and 21 had genotype 1 and genotype 2, respectively.

The demographic and clinical characteristics of the HBV and HCV groups are presented in Table II. No significant differences were observed in the sex ratio between the groups. The median age \pm standard deviation was significantly higher in the $\mathrm{HCV}$ (67 \pm 16.4 years) than in the HBV group $(58 \pm 18.0$ years; $\mathrm{P}=0.02)$. No significant differences in age were observed between the sexes in either group. Female patients were older than male patients in the HCV group, although this difference was not significant $(\mathrm{P}=0.06)$; however, female patients with $\mathrm{HCV}$ were older than the HBV and HCV male patients $(\mathrm{P}=0.02)$. Similar tendencies were observed for the year of birth between sexes and the HBV and HCV groups. As regards the comparison of laboratory data between the HBV and HCV groups, the AST and ALT values were significantly higher in the HCV than in the HBV group (AST, P<0.001; ALT, $\mathrm{P}=0.003$ ). No significant differences were observed in the platelet count or PT values between the HBV and HCV groups (Table II).

Subsequently, the types of opportunities/events the patients in the HBV and HCV groups which led them to become aware of their infection were analyzed. The majority of the patients (96/126) had become aware of their HBV or HCV infection by chance (e.g., during a checkup or follow-up for another disease, other than liver disease; Table III). These opportunities to become aware of a chronic HBV or HCV infection involved a pre-operative search for $\mathrm{HBV}$ and $\mathrm{HCV}$ infection and a search for transaminase value elevations during follow-up for 
Table I. Details of patients with chronic hepatitis B and C infection.

Chronic hepatitis B

\begin{tabular}{|c|c|c|c|c|c|c|c|}
\hline Antibody/genotype & Male (44) & Female (19) & Total (63) & Antibody/genotype & Male (36) & Female (27) & Total (63) \\
\hline HBsAg-positive & 42 & 19 & 61 & HCVAb-positive & 36 & 27 & 63 \\
\hline HBsAg-negative & 2 & 0 & 2 & HCVAb-negative & 0 & 0 & 0 \\
\hline HBeAg-positive & 12 & 3 & 15 & HCV RNA-positive & 36 & 27 & 63 \\
\hline HBeAg-negative & 32 & 16 & 48 & HCVRNA-negative & 0 & 0 & 0 \\
\hline HBeAb-positive & 31 & 15 & 46 & Genotype $1^{\mathrm{a}}$ & 17 & 18 & 35 \\
\hline $\mathrm{HBe} \mathrm{Ab}$-negative & 13 & 4 & 17 & Genotype $2^{b}$ & 14 & 7 & 21 \\
\hline HBV DNA-positive & 40 & 15 & 55 & No data ${ }^{c}$ & 5 & 2 & 7 \\
\hline HBV DNA-negative & 4 & 4 & 8 & & & & \\
\hline HBV DNA-positive & & & & & & & \\
\hline and $\mathrm{HBs} \mathrm{Ag}$-positive & 38 & 15 & 53 & & & & \\
\hline Genotype A & 2 & 0 & 2 & & & & \\
\hline Genotype B & 4 & 3 & 7 & & & & \\
\hline Genotype C & 26 & 9 & 35 & & & & \\
\hline No data ${ }^{c}$ & 12 & 7 & 19 & & & & \\
\hline
\end{tabular}

Chronic hepatitis C

${ }^{a}$ Genotype 1 includes serotype 1 , genotype $1 \mathrm{a}$ and genotype $1 \mathrm{~b}$. ${ }^{\mathrm{b}}$ Genotype 2 includes serotype 2 , genotype $2 \mathrm{a}$ and genotype $2 \mathrm{~b}$. ${ }^{\mathrm{c}} \mathrm{No}$ data includes the cases which were unmeasured and it was thus unable to identify the genotype. $\mathrm{HBsAg}$, hepatitis B virus surface antigen; $\mathrm{HBe} A g$, hepatitis B virus e-antigen; $\mathrm{HBeAb}$, anti-hepatitis B virus e-antigen antibody; HCVAb, anti-hepatitis C virus antibody.

Table II. Comparison of the characteristics between the chronic hepatitis B group and C group.

\begin{tabular}{lccc}
\hline Characteristic & Chronic hepatitis B & P-value & Chronic hepatitis C \\
\hline N (M/F) & $63(44 / 19)$ & 0.19 & $63(36 / 27)$ \\
Age (all) years, median \pm SD & $58 \pm 18.0(18-86)$ & 0.02 & $67 \pm 16.4(19-88)$ \\
(M) age years, median \pm SD & $55 \pm 17.4(18-84)^{\mathrm{a}}$ & 0.13 & $59.5 \pm 15.5(19-80)^{\mathrm{b}}$ \\
(F) age years, median \pm SD & $63 \pm 19.5(23-86)$ & 0.12 & $72 \pm 16.7(25-88) \mathrm{f}$ \\
Year of birth (all) median \pm SD & $1955 \pm 18.0(1927-1999)$ & 0.03 & $1949 \pm 16.5(1925-1994)$ \\
(M) median \pm SD & $1961 \pm 17.9(1927-1999)^{\mathrm{c}}$ & 0.17 & $1953.5 \pm 16.1(1930-1994)^{\mathrm{d}}$ \\
(F) median \pm SD & $1949 \pm 18.4(1929-1989)$ & 0.1 & $1942 \pm 16.2(1925-1984)^{\mathrm{e}}$ \\
AST (IU/l), median \pm SD & $27 \pm 35(13-210)$ & $<0.001$ & $53 \pm 50(17-314)$ \\
ALT (IU/l), median \pm SD & $28 \pm 53(8-270)$ & 0.003 & $48 \pm 69(7-355)$ \\
Platelet $\left(x 10^{3} / \mathrm{mm}^{3}\right)$, median \pm SD & $180 \pm 65(59-502)$ & 0.06 & $159 \pm 62(53-370)$ \\
PT $(\%)$, median \pm SD & $92 \pm 16(42-120)$ & 0.52 & $91 \pm 15(39-126)$ \\
\hline
\end{tabular}

${ }^{\mathrm{a}} \mathrm{P}=0.6$, vs. females in HVB group. ${ }^{\mathrm{b}} \mathrm{P}=0.06$ vs. females in $\mathrm{HCV}$ group. ${ }^{\mathrm{c}} \mathrm{P}=0.6$, vs. year of birth of females in HBV group. ${ }^{\mathrm{d}} \mathrm{P}=0.08$, vs. year of birth of females in HCV group. ${ }^{\mathrm{e}} \mathrm{P}=0.02$, vs. HBV and $\mathrm{HCV}$ male patients. ${ }^{\mathrm{f}} \mathrm{P}=0.03$, vs. HBV and HCV male patients. AST, aspartate aminotransferase; ALT, alanine aminotransferase; PT, prothrombin time; M, male; F, female. N, number of cases; SD, standard deviation.

diseases other than liver disease. On the other hand, $20 \%$ of the patients $(24 / 126)$ had become aware of their infection through detection during a health checkup (Table III). With respect to these patients, a comparison between the HBV and $\mathrm{HCV}$ groups revealed that the patients were significantly younger in the HBV group than in the HCV group $(\mathrm{P}=0.049$; Table IV). This tendency was also observed between males in the HBV and HCV groups $(\mathrm{P}=0.01)$, but not between females With respect to the patients whose infection had been detected by chance during a checkup or follow-up for a disease other than liver disease, the median age did not differ significantly between the HBV and HCV groups. Among the patients in the HBV group, those whose infection had been detected during a health checkup were significantly younger than those whose infection had been detected by chance during follow-up for a disease other than liver disease $(\mathrm{P}=0.016)$; however, this tendency was not recognized when comparing the patients in the HCV group (Table IV). The patients with HBV detected during a health checkup were younger than the other patients (patients with HCV detected during a health checkup and the 
Table III. Comparison of opportunities/events that led to the patients becoming aware of their chronic hepatitis B and C virus infection.

\begin{tabular}{lccc}
\hline Opportunities that led to awareness of viral infection & Chronic hepatitis B & Chronic hepatitis C & Chronic hepatitis B + C \\
\hline Health checkup (male/female) & $12(10 / 2)$ & $12(7 / 5)$ & $24(17 / 7)$ \\
During the follow-up of other diseases (male/female) & $46(32 / 14)$ & $50(28 / 22)$ & $96(60 / 36)$ \\
Blood donation (male/female) & $1(0 / 1)$ & $0(0 / 0)$ & $1(0 / 1)$ \\
Delivery (male/female) & $1(0 / 1)$ & $0(0 / 0)$ & $1(0 / 1)$ \\
etc. (male/female) & $3(2 / 1)$ & $1(1 / 0)$ & $4(3 / 1)$ \\
Total & $63(44 / 19)$ & $63(36 / 27)$ & $126(80 / 46)$
\end{tabular}

Table IV. Comparison of the age of patients who became aware of their chronic hepatitis virus B and C infection.

\begin{tabular}{|c|c|c|c|}
\hline $\begin{array}{l}\text { Opportunities which led to patients } \\
\text { becoming aware of having a viral infection }\end{array}$ & $\begin{array}{l}\text { Chronic hepatitis } B \\
\text { Year of age (median } \pm \text { SD) }\end{array}$ & P-value & $\begin{array}{c}\text { Chronic hepatitis } \mathrm{C} \\
\text { Year of age (median } \pm \mathrm{SD})\end{array}$ \\
\hline Health checkup & $40 \pm 9.9^{\mathrm{a}, \mathrm{c}}$ & 0.049 & $58 \pm 21.6^{\mathrm{b}}$ \\
\hline Male & $37 \pm 5.7$ & 0.01 & $59 \pm 18.6$ \\
\hline Female & $60.5 \pm 3.5$ & 0.7 & $57 \pm 27.5$ \\
\hline During the follow-up of other diseases & $63.5 \pm 17.2$ & 0.21 & $67 \pm 14.8$ \\
\hline Male & $63.5 \pm 17$ & 0.81 & $62.5 \pm 15$ \\
\hline Female & $65.5 \pm 18.1$ & 0.16 & $72.5 \pm 13.3$ \\
\hline
\end{tabular}

${ }^{\mathrm{a}} \mathrm{P}=0.016$, vs. patients with $\mathrm{HBV}$ detected during the follow-up for other diseases; ${ }^{\mathrm{b}} \mathrm{P}=0.46$, vs. patients with $\mathrm{HCV}$ detected during the follow-up for other diseases; ${ }^{c} \mathrm{P}=0.0007$, patients with $\mathrm{HBV}$ detected during a health checkup vs. patients with HCV detected during a health checkup, and patients with $\mathrm{HBV}$ and $\mathrm{HCV}$ detected during a health checkup or follow-up for a disease other than liver disease. SD, standard deviation.

Table V. Comparison of the age of patients who became aware they had chronic HBV or HCV infection, with the simultaneous presence of HCC.

\begin{tabular}{lccc}
\hline & Chronic hepatitis B & P-value & Chronic hepatitis C \\
\hline HCC $(+/-)$ & $4 / 59$ & 0.69 & $3 / 60$ \\
HCC + (age of yeas, median \pm SD) & $68.5 \pm 10.5^{\mathrm{a}}$ & 0.15 & $78 \pm 5.3^{\mathrm{b}}$ \\
HCC- (age of yeas, median \pm SD) & $58 \pm 18.2^{\mathrm{c}}$ & 0.03 & $65 \pm 16.3$ \\
\hline
\end{tabular}

${ }^{\mathrm{a}} \mathrm{P}=0.32$, vs. $\mathrm{HBV}$ without $\mathrm{HCC} .{ }^{\mathrm{b}} \mathrm{P}=0.08$, vs. $\mathrm{HCV}$ without $\mathrm{HCC} .{ }^{\mathrm{c}} \mathrm{P}=0.048$, patients with $\mathrm{HBV}$ without $\mathrm{HCC}$ vs. other patients. $\mathrm{HCC}$, hepatocellular carcinoma; SD, standard deviation.

patients with HBV and HCV detected during a health checkup or follow-up for a disease other than liver disease; $\mathrm{P}=0.0007$ ).

In total, seven patients (four with HBV infection and three with $\mathrm{HCV}$ infection) received a diagnosis of HCC and chronic hepatitis infection simultaneously (Table V). The patients in the $\mathrm{HCV}$ group with $\mathrm{HCC}$ were older than those without, although this difference was not significant $(\mathrm{P}=0.08)$. However, the patients in the HBV group without $\mathrm{HCC}$ were younger than those without $\mathrm{HCC}$ in the $\mathrm{HCV}$ group $(\mathrm{P}=0.03)$. In addition, patients with $\mathrm{HBV}$ without $\mathrm{HCC}$ were younger than the other patients $(\mathrm{P}=0.0048)$.

\section{Discussion}

In the present study, $22 \%$ of patients with chronic HBV infection and $24 \%$ with chronic $\mathrm{HCV}$ infection became aware of their infection for the first time upon referral to our hospital. Patients with genotype $\mathrm{C}$ were most common in the HBV group, and the distribution of HBV genotype tended to be similar to that reported in a previous study in Japan (21). Among the patients in the HCV group, more had genotype 1 than genotype 2, and the distribution of the HCV genotype also tended to be similar to that reported in a previous study in Japan (22). Therefore, the population of patients first becoming aware of their chronic HBV and HCV infections on referral to the hospital in the present study can be generalized to the standard population of patients with chronic $\mathrm{HBV}$ and $\mathrm{HCV}$ infections in Japan.

The results of the present study revealed that patients first becoming aware of their $\mathrm{HCV}$ infection were older than those first becoming aware of their HBV infection. In addition, 
female patients with HCV first becoming aware of their chronic hepatitis were older than the other patients. Thus, earlier awareness of chronic hepatitis virus infection may benefit patients with chronic HCV infection and female patients more than patients with chronic HBV and/or male patients in Japan. Since aging is independently associated with the prevalence of $\mathrm{HCC}$ in patients with chronic HCV (23), a delay in awareness regarding $\mathrm{HCV}$ infection is likely to increase disease severity (e.g., HCC, decompensated cirrhosis). In the present study, patients with chronic $\mathrm{HCV}$ infection and $\mathrm{HCC}$ were older than those without HCC. In addition, it appeared that more patients had active chronic hepatitis infection in the HCV than in the HBV group due to elevated transaminase levels. Therefore, chronic hepatitis infections, particularly HCV infection, need to be identified earlier as these patients, particularly female patients, may continue to live with undetected active hepatitis and/or HCC and not receive appropriate treatment.

The findings of the present study revealed that the majority patients had been aware of their chronic hepatitis infection through checkups during follow-up for diseases other than liver disease. The awareness of the chronic hepatitis virus infection through health checkups was not as common as that by checkups during follow-up for other diseases in both the HBV and HCV groups, which suggests that the detection of chronic hepatitis infection in health checkups is currently used insufficiently in Japan, even though the Japanese government has recommended screening for viral hepatitis (24). On the other hand, patients who became aware of their chronic hepatitis infection through a health checkup were younger than those who became aware of their infection through a checkup during follow-up for other diseases; this tendency was observed in the $\mathrm{HBV}$, but not in the HCV group. Taken together, these findings indicate that health checkups may contribute to the awareness of chronic HBV infection in younger populations. However, patients who became aware of their chronic HCV infection through a health checkup were older than those with chronic HBV infection, particularly males. Although the reason for this difference is unclear, Tatemichi et al (25) reported that only 5.23 and $3.82 \%$ of Japanese workers had been screened for $\mathrm{HBV}$ and $\mathrm{HCV}$ infection, respectively, and significantly more workers had been tested for HBV than for HCV infection. The use of hepatitis virus screening tools during health checkups varies between organizations (e.g., official health checkups vs. health checkups for company employees). HBV infection is recognized as an occupational exposure risk for health care workers and laboratory technicians (25), which may be attributed to the original Japanese Union Health Insurance system in which beneficiaries underwent comprehensive health examinations as part of a mandatory health checkup; these examinations included screening for HBV, but not HCV (25). In female patients, the age when they became aware of their chronic hepatitis virus infection was high, even though it was HBV infection. Female Japanese patients may have fewer opportunities for health checkups of company employees, as there is a larger proportion of non-regular employees among Japanese female than Japanese male workers (26).

As regards the patients who became aware of their chronic hepatitis infection during follow-up for a disease other than liver disease, the modality for detecting chronic hepatitis infection is a routine checkup on admission or before an operation in some patients (data not shown). Some of these patients had not had their chronic hepatitis infection detected by their family doctor before being presented with these opportunities. Therefore, the Japanese government policy regarding hepatitis virus screening may not be sufficiently recognized by patients or family doctors, which suggests the importance of informing family doctors of the need to screen patients for chronic hepatitis infection and ensure that they are aware of their infection as soon as possible, even if they do not show abnormal transaminase levels, as some of the patients in the present study, particularly those with HBV infection, had normal transaminase levels.

The present study does have some limitations. First, the sample size was small, and the study was conducted in single center within one area of Japan. However, in Japan, national healthcare insurance is a system in which everyone can access the healthcare services they need without incurring financial hardship (27). In addition, Japan has no barriers to accessing health care, including financial, geographic, cultural, or informational, which makes it easier for patients to access (27). Therefore, the results of the present study may be generalizable to other areas of Japan; however, more cases from many other areas in Japan need to be collected and analyzed in the future. Furthermore, information on whether the participants had a history of chronic hepatitis infection depended on patient interviews; thus, it is possible that some patients may have forgotten about a previous diagnosis. However, it was considered that this would not have substantially affected the results, since past detection of chronic hepatitis infection would not have been meaningful to such patients, as it did not cause them to seek further treatment and/or assessment.

In conclusion, the results of the present study indicate that health checkups are useful for detecting chronic HBV infection earlier; however, for female patients and those with chronic $\mathrm{HCV}$, no advantage was found in becoming aware of their infection during a health checkup compared with by chance during follow-up for diseases other than liver disease. The majority Japanese patients with chronic hepatitis infection are older; therefore, it is important to improve screening for hepatitis virus infection for elderly persons. To identify more cases of chronic hepatitis infection who are unaware of their infection as soon as possible, the necessarily of screening for hepatitis virus infection should be emphasized, especially among females and elderly persons. To this end, primary-care doctors should also consider expanding screening for patients who are unaware of whether they are infected with chronic hepatitis virus, even if their transaminase levels are normal.

\section{Acknowledgements}

Not applicable.

\section{Funding}

No funding was received.

\section{Availability of data and materials}

The datasets used and/or analyzed during the current study are available from the corresponding author on reasonable request. 


\section{Authors' contributions}

HO was involved in the conception and design of the study, and in the writing and preparation of the manuscript and tables. HA, KN, ST, TT, HK, TSakuno, YI, HT, SM, TSase, TSaito, KM and AN collected the data. All authors revised the manuscript, approved the manuscript to be published, and agree to be accountable for all aspects of the work in ensuring that questions related to the accuracy or integrity of any part of the work are appropriately investigated and resolved. $\mathrm{HO}$ and AN confirm the authenticity of all the raw data. All authors have read and approved the final manuscript.

\section{Ethics approval and consent to participate}

Oral informed consents, including the statement of agreement to the use of their samples in scientific research were obtained from each patient at the first medical examination in the Outpatient Department of Suzuka General Hospital. The present study was approved by the Ethics Committee of Suzuka General Hospital.

\section{Patient consent for publication}

Not applicable.

\section{Competing interests}

The authors declare that they have no competing interests.

\section{References}

1. Schweitzer A, Horn J, Mikolajczyk RT, Krause G and Ott JJ: Estimations of worldwide prevalence of chronic hepatitis B virus infection: A systematic review of data published between 1965 and 2013. Lancet 386: 1546-1555, 2015.

2. Mohd Hanafiah K, Groeger J, Flaxman AD and Wiersma ST: Global epidemiology of hepatitis $\mathrm{C}$ virus infection: New estimates of age-specific antibody to HCV seroprevalence. Hepatology 57: 1333-1342, 2013.

3. Chung H, Ueda T and Kudo M: Changing trends in hepatitis $\mathrm{C}$ infection over the past 50 years in Japan. Intervirology 53: 39-43, 2010.

4. de Martel C, Maucort-Boulch D, Plummer M and Franceschi S: World-wide relative contribution of hepatitis $\mathrm{B}$ and $\mathrm{C}$ viruses in hepatocellular carcinoma. Hepatology 62: 1190-1200, 2015.

5. Su TH and Kao JH: Improving clinical outcomes of chronic hepatitis B virus infection. Expert Rev Gastroenterol Hepatol 9: 141-154, 2015.

6. Yokosuka O, Takaguchi K, Fujioka S, Shindo M, Chayama K, Kobashi H, Hayashi N, Sato C, Kiyosawa K, Tanikawa K, et al: Long-term use of entecavir in nucleoside-naïve Japanese patients with chronic hepatitis B infection. J Hepatol 52: 791-799, 2010.

7. Ono A, Suzuki F, Kawamura Y, Sezaki H, Hosaka T, Akuta N, Kobayashi M, Suzuki Y, Saitou S, Arase Y, et al: Long-term continuous entecavir therapy in nucleos(t)ide-naïve chronic hepatitis B patients. J Hepatol 57: 508-514, 2012.

8. Sugiyama A, Ohisa M, Nagashima S, Yamamoto C, Chuon C, Fujii T, Akita T, Katayama K, Kudo Y and Tanaka J: Reduced prevalence of hepatitis B surface antigen positivity among pregnant women born after the national implementation of immunoprophylaxis for babies born to hepatitis B virus-carrier mothers in Japan. Hepatol Res 47: 1329-1334, 2017.

9. de Fraga RS, Van Vaisberg V, Mendes LCA, Carrilho FJ and Ono SK: Adverse events of nucleos(t)ide analogues for chronic hepatitis B: A systematic review. J Gastroenterol 55: 496-514, 2020.
10. Kumada H, Suzuki Y, Ikeda K, Toyota J, Karino Y, Chayama K, Kawakami Y, Ido A, Yamamoto K, Takaguchi K, et al: Daclatasvir plus asunaprevir for chronic HCV genotype $1 \mathrm{~b}$ infection. Hepatology 59: 2083-2091, 2014.

11. Omata M, Nishiguchi S, Ueno Y, Mochizuki H, Izumi N, Ikeda F, Toyoda H, Yokosuka O, Nirei K, Genda T, et al: Sofosbuvir plus ribavirin in Japanese patients with chronic genotype $2 \mathrm{HCV}$ infection: An open-label, phase 3 trial. J Viral Hepat 21: 762-768, 2014.

12. Chayama K, Notsumata K, Kurosaki M, Sato K, Rodrigues L Jr, Setze C, Badri P, Pilot-Matias T, Vilchez RA and Kumada H: Randomized trial of interferon- and ribavirin-free Ombitasvir/paritaprevir/ritonavir in treatment-experienced hepatitis C virus-infected patients. Hepatology 61: 1523-1532, 2015.

13. Mizokami M, Yokosuka O, Takehara T, Sakamoto N, Korenaga M, Mochizuki H, Nakane K, Enomoto H, Ikeda F, Yanase M, et al: Ledipasvir and sofosbuvir fixed-dose combination with and without ribavirin for 12 weeks in treatment-naive and previously treated Japanese patients with genotype 1 hepatitis C: An open-label, randomised, phase 3 trial. Lancet Infect Dis 15: 645-653, 2015.

14. Suda G, Furusyo N, Toyoda H, Kawakami Y, Ikeda H, Suzuki M, Arataki K, Mori N, Tsuji K, Katamura Y, et al: Daclatasvir and asunaprevir in hemodialysis patients with hepatitis $\mathrm{C}$ virus infection: A nationwide retrospective study in Japan. J Gastroenterol 53: 119-128, 2018.

15. Akuta N, Sezaki H, Suzuki F, Kawamura Y, Hosaka T, Kobayashi M, Kobayashi M, Saitoh S, Suzuki Y, Arase Y, et al: Favorable efficacy of daclatasvir plus asunaprevir in treatment of elderly Japanese patients infected with HCV genotype $1 \mathrm{~b}$ aged 70 and older. J Med Virol 89: 91-98, 2017.

16. Heathcote EJ, Marcellin P, Buti M, Gane E, De Man RA, Krastev Z, Germanidis G, Lee SS, Flisiak R, Kaita K, et al: Three-year efficacy and safety of tenofovir disoproxil fumarate treatment for chronic hepatitis B. Gastroenterology 140: 132-143, 2011.

17. Marcellin P, Gane E, Buti M, Afdhal N, Sievert W, Jacobson IM, Washington MK, Germanidis G, Flaherty JF, Aguilar Schall R, et al: Regression of cirrhosis during treatment with tenofovir disoproxil fumarate for chronic hepatitis B: A 5-year open-label follow-up study. Lancet 381: 468-475, 2013.

18. Backus LI, Belperio PS, Shahoumian TA and Mole LA: Impact of sustained virologic response with direct-acting antiviral treatment on mortality in patients with advanced liver disease. Hepatology 69: 487-497, 2019.

19. Nagai K, Ide K, Kawasaki Y, Tanaka-Mizuno S, Seto K, Iwane S, Eguchi Y and Kawakami K: Estimating the cost-effectiveness of screening for hepatitis $\mathrm{C}$ virus infection in Japan. Hepatol Res 50: 542-556, 2020.

20. El-Serag HB, Kanwal F, Richardson P and Kramer J: Risk of hepatocellular carcinoma after sustained virological response in Veterans with hepatitis C virus infection. Hepatology 64: 130-137, 2016.

21. Orito E, Ichida T, Sakugawa H, Sata M, Horiike N, Hino K, Okita K, Okanoue T, Iino S, Tanaka E, et al: Geographic distribution of hepatitis B virus (HBV) genotype in patients with chronic HBV infection in Japan. Hepatology 34: 590-594, 2001.

22. Toyoda H, Kumada T, Takaguchi K, Shimada N and Tanaka J: Changes in hepatitis C virus genotype distribution in Japan. Epidemiol Infect 142: 2624-2628, 2014.

23. Ikeda K, Saitoh S, Koida I, Arase Y, Tsubota A, Chayama K, Kumada $\mathrm{H}$ and Kawanishi M: A multivariate analysis of risk factors for hepatocellular carcinogenesis: A prospective observation of 795 patients with viral and alcoholic cirrhosis. Hepatology 18: 47-53, 1993.

24. Ministry of Health, Labour and Welfare: Basic guidelines for promotion of control measures for hepatitis. http://www.mhlw. go.jp/bunya/kenkou/kekkakukansenshou09/pdf/hourei-17e.pdf. Accessed August 21, 2017.

25. Tatemichi M, Furuya H, Nagahama S, Takaya N, Shida Y, Fukai K, Owada S, Endo H, Kinoue T and Korenaga M: A nationwide cross-sectional survey on hepatitis B and C screening among workers in Japan. Sci Rep 10: 11435, 2020.

26. Gender Equality Bureau, Cabinet Office, Government of Japan: White Paper on Gender Equality 2020-Summary. 2020. https://www.gender.go.jp/english_contents/about_ danjo/whitepaper/pdf/ewp2020.pdf. Accessed July 31. 2020.

27. Sasaki T, Izawa M and Okada Y: Current trends in health insurance systems: OECD countries vs. Japan. Neurol Med Chir (Tokyo) 55: 267-275, 2015.

This work is licensed under a Creative Commons Attribution-NonCommercial-NoDerivatives 4.0 International (CC BY-NC-ND 4.0) License. 